\section{Therapist adherence to a treatment manual influences outcome and dropout rates: Results from a multicenter randomized clinical CBT trial for panic disorder with agoraphobia}

\author{
Hauke, Christina \\ Technical University of Dresden, Germany (christinahauke@gmx.de)
}

Gloster, Andrew T.

Technical University of Dresden, Germany (gloster@psychologie.tu-dresden.de)

Gerlach, Alexander

University of Cologne, Germany (alexander.gerlach@uni-koeln.de)

Hamm, Alfons

Ernst-Moritz-Arndt University Greifswald, Germany (hamm@uni-greifswald.de)

Deckert, Jürgen

University of Würzburg, Germany (Deckert_J@klinik.uni-wuerzburg.de)

Fehm, Lydia

University of Berlin, Germany (Lydia.Fehm@hu-berlin.de)

Alpers, Georg W.

University of Mannheim, Germany (alpers@uni-mannheim.de)

Kircher, Tilo

Philipps University Marburg, Germany (psychiat @ med.uni-marburg.de)

Ströhle, Andreas

Universitätsmedizin Berlin, Germany (andreas.stroehle@charite.de)

Arolt, Volker

University of Münster, Germany (volker.arolt@ukmuenster.de)

Wittchen, Hans-Ulrich

Technical University of Dresden, Germany (wittchen@psychologie-tu-dresden.de)

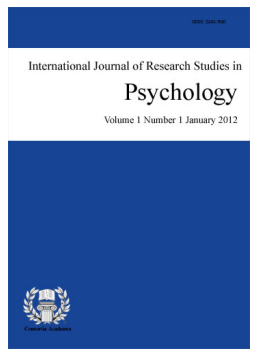

ISSN: 2243-7681 Online ISSN: 2243-769X

OPEN ACCESS

Received: 31 January 2013

Revised: 9 April 2012 DOI: $10.5861 /$ ijrsp. 2013.335

Accepted: 10 August 2013

Available Online: 16 October 2013

\title{
Abstract
}

Therapist adherence has been shown to contribute to the effectiveness of treatment interventions. The role in a patient's decision to drop out of treatment, however, is unknown. This study investigates whether therapist adherence affects clinical outcome and the risk for dropout. Patients diagnosed with panic disorder with agoraphobia $(\mathrm{N}=265)$ were treated in one of two CBT variations: with $(\mathrm{T}+)$ and without $(\mathrm{T}-)$ explicit therapist-guided exposure. Significant associations between lower levels of adherence and symptomatic improvement were observed in treatment completers in the $\mathrm{T}$ - condition and dropouts in $\mathrm{T}+$ condition suggesting that adherence-outcome relations are potentially contributed by patient and treatment characteristics. Moreover, our results propose that patient related difficulties with exposure procedures may lead to lower adherence and dropout.

Keywords: treatment integrity; cognitive behavior therapy; exposure; anxiety; therapist variables 


\section{Therapist adherence to a treatment manual influences outcome and dropout rates: Results from a multicenter randomized clinical CBT trial for panic disorder with agoraphobia}

\section{Introduction}

Therapist compliance with an intended intervention is a prerequisite for understanding the mechanisms of action in psychotherapy treatment (Perepletchikova \& Kazdin, 2005). Manual-based interventions facilitate the comparison of therapies on potentially confounding unspecific parameters (Heimberg \& Becker, 1994) and ensure tailored treatment elements to optimize the mechanisms of change (Luborsky \& DeRubeis, 1984). In spite of that, the advantages of manualized treatment implementation might not apply unrestrictedly for the association to treatment outcome. Theoretically, high levels of therapist adherence should be associated with better outcomes if relevant treatment elements are delivered as intended (e.g., Emmelkamp, Bouman, \& Blaauw, 1994; Schulte, Künzel, Pepping, \& Schulte-Bahrenberg, 1992). Empirically studies showed, however, that high adherence to a manual is negatively associated with symptomatic improvement (e.g., DeRubeis \& Feeley, 1990, in CBT for depression; Huey, Henggeler, Brondino, \& Pickrel, 2000, in multisystemic therapy for delinquent behavior). Research of Barber et al. (2006, in individual drug counseling) and Hogue et al. (2008, in CBT and multidimensional family therapy for adolescent substance use) suggest even curvilinear relationships between adherence and outcome. The disagreement on the role of adherence in the treatment process might be based on the fact that prior studies failed to examine patients who discontinued treatment. This is problematic because potential differences between completers and dropouts could bias estimates of complete samples.

Analyzing the overall sample might be especially important when implementing exposure-based CBT, a treatment that needs to be adapted to patients who have difficulty fully engaging in this effortful treatment. To our knowledge, only White et al. (2010) investigated the association between treatment factors and dropout in CBT for patients with panic disorder with agoraphobia (PD/AG) suggesting that adherence did not predict treatment complementation. Based on clinical considerations, the importance of therapist adherence might potentially differ across treatment elements and individual patient requirements (Perepletchikova \& Kazdin, 2005). A high anxious patient, for instance, with strong avoidance behavior and thoughts of dropping out might require more time for exposures than intended in the treatment manual. In this case, it is comprehensible that the therapist adheres differently to a manual compared to a therapist treating a patient who will definitely complete the treatment. The optimal level of adherence in exposure treatment manuals may also vary as a function of the reasons for dropout and the timing of the dropout. Patients who are afraid or not motivated enough for exposure in situ might drop out at time points or due to reasons which are related to exposure exercises. Consequently, the level of therapist adherence before and during exposure elements seems to be an important factor for treatment outcome. Keeping these points in mind, it is highly recommended to examine the association of adherence and outcome in the entire patient cohort including completers and dropouts.

The lack of strong and consistent findings in the literature may also result from therapist characteristics that influence the degree of adherence (Smith, Daunic, \& Taylor, 2007; Webb et al., 2010) such as therapist competence and experience (Lambert \& Bergin, 1994; Perepletchikova \& Kazdin, 2005). Competence refers to the quality of treatment implementation and reflects the skills of the therapist such as the appropriate adaption of interventions and procedures, the style of communication and the ability for clinical reasoning (Perepletchikova \& Kazdin, 2005). A very low level of competence is assumed to not influence treatment outcome if a therapist is adherent enough to the protocol, whereas a medium to high level of competence might affect the relation between lower levels of adherence and outcome (Barber et al., 2006, CBT in 95 cocaine-dependent outpatients). Therapist experience was found to be associated with competence and refers to the amount of theoretical and practical knowledge of a therapist according to a special treatment or patient group (Siqueland et al., 2000). Contrary to common belief, therapists with more experience tend to have lower levels of adherence than less 
experienced therapists (Henry et al., 1993; Siqueland et al., 2000). Some authors explained this by stating that experienced therapists stick to their established ways of conducting therapy (Margison et al., 2000) and have more barriers learning new therapeutic strategies (Perepletchikova \& Kazdin, 2005). Considering the potential influence of competence and experience might help to identify the core mechanisms of adherence to a CBT manual in symptomatic outcome in patients with PD/AG.

In the present study, we examined the association between therapist adherence and both treatment outcome and dropout risk for patients with PD/AG treated with an exposure-based CBT. We hypothesized that adherence levels (1) differ between therapists who treated completers vs. those who treated dropouts, (2) are related to timing and reasons of dropouts, and (3) are related to treatment outcome. Furthermore, all these associations were examined with and without the influence of therapist competence and experience.

\section{Methods}

\subsection{Trial design}

These data stem from a multicenter study for patients with PD/AG $(n=369)$ randomized either to one of two conditions of CBT or to a waitlist control group which was excluded from the present analyses. The active treatment groups were based on a 12-session manualized treatment protocol (Lang, Helbig-Lang, Westphal, Gloster, \& Wittchen, 2011) carried out over approximately 6 weeks, and followed by two booster sessions. The CBT was based on established manuals (Craske \& Barlow, 2007) which were previously evaluated as effective for patients with PD/AG in several clinical trials (Barlow, Gorman, Shear \& Woods (2000) and developments in exposure-based CBT (Baker-Morrissette, Spiegel, \& Heinrichs, 2005; Richard, Lauterbach, \& Gloster, 2007). The study manual consisted of psychoeducation, behavioral analysis of the patients' symptoms and associated coping behaviors, rationale for exposure (i.e., sufficiently long and repeated exposure to feared stimuli without utilization of safety behaviors leads to fear reduction), interoceptive exposure, standardized in situ exposure (i.e., bus, shopping mall, and forest), anticipatory anxiety, individualized in situ exposure (i.e., of the patients' most feared situations), and relapse prevention. In situ exposures were either accompanied by the therapist $(\mathrm{T}+)$ or thoroughly planned including mental rehearsal, anticipation of problems and with identical instructions not to use safety behaviors in the therapy room (T-). Methods and design of the study have been described in greater detail elsewhere (Gloster et al., 2009).

\subsection{Therapists}

Therapists $(\mathrm{N}=58)$ were advanced-level clinical psychology graduate students and post-docs experienced in CBT of anxiety disorders. During a three-day intensive training workshop, therapists were trained to follow the manual specifications and required to pass a certification process consisting of recorded role-plays scored by experts. During treatment, all therapists were involved in weekly manual-specific supervision.

\subsection{Patients}

The present study comprises $\mathrm{N}=265$ patients whose took part in the active treatment of the overall outcome study (Gloster et al., 2009, 2011). Patients were recruited from ongoing clinical care, physician referral and via additional advertisements in various media outlets across eight study centers. Eligible for inclusion were those who met DSM-IV-TR (Association, 2000) diagnostic criteria for PD/AG as validated by a standardized computer-administered personal Composite International Diagnostic Interview (CAPI-WHO-CIDI; DIAX-CIDI version, Wittchen, \& Pfister, 1997); a clinical interview score $\geq 18$ on the Structured Interview Guide for the Hamilton Anxiety Scale (SIGH-A; Shear et al., 2001) in Anxiety and Depression, a score $\geq 4$ on the Clinical Global Impressions (CGI; Guy, 1976) Scale, and aged between 18 to 65. Patients were excluded if they reported clinically significant suicidal intent, not comply with the study requirements, met diagnostic criteria for any Psychotic or Bipolar Disorder, Borderline Personality Disorder, current Alcohol Dependence or had a medical 
Hauke et al.

condition that could explain the patient's symptoms. Other current comorbid diagnoses were allowed unless they were of primary clinical concern of the treating institution. Patients had to agree cease taking psychopharmacological medication or have concomitant other psychotherapy. Support and therapy was provided for patients who were excluded as well as those previously in the wait list condition.

\subsection{Definition of completers and dropouts}

Treatment completion was defined as finishing the first 12 sessions irrespective of the two booster sessions $(\mathrm{n}=220 ; 119 \mathrm{~T}+; 101 \mathrm{~T}-)$. Dropout was defined as terminating the treatment before session 12 without the therapist's endorsement $(n=45 ; 24 T+; 21 T$-). Dropouts after baseline assessment but prior to the first session were excluded from analyses because of the absence of recorded therapy sessions. The definition of dropouts differs from the overall outcome study (Gloster et al., 2011) but is consistent with previous theoretical recommendations for studies targeting dropouts (e.g., Reis \& Brown, 1999; Wierzbicki \& Pekarik, 1993). Completers and dropouts did not differ in their socio-demographic and clinical characteristics (Table 1).

Across treatment conditions, patients were grouped by timing and reasons of dropout. Because exposure was considered as a core element in our study timing of dropout was split into early (not focusing exposure in situ; session 1-4; $\mathrm{n}=7,15.6 \%$ ), intermediate (decision for exposure in situ; session 5-6; $\mathrm{n}=15,33.3 \%$ ), and late (conducting and discussing exposure in situ; session 7-12; $\mathrm{n}=23,51.1 \%$ ) dropout. Reasons for dropout were specified prior to the study and documented by the therapist. Patients were divided into those who dropped out due to exposure-related reasons such as too anxious $(n=6,13.3 \%)$ or not motivated enough for exposure $(n=6$, $13.3 \%)$ vs. reasons related to other issues such as organizational problems $(\mathrm{n}=8,17.8 \%)$, interrupted contact ( $\mathrm{n}$ $=8,17.8 \%)$, symptom improvement $(n=4,8.9 \%)$, symptom deterioration $(n=2,4.4 \%)$, more relevance of other disorders $(\mathrm{n}=1,2.2 \%)$, and other reasons $(\mathrm{n}=10,22.2 \%)$, e.g. somatic disease or problems with family and relationship.

\subsection{Rating procedure of therapist adherence}

All treatment sessions were videotaped except those portions of the therapy that occurred outside the therapy room (i.e., in situ exposure). Nevertheless, the parts of these sessions that occurred in the room prior to leaving (preparation) and returning (evaluation) were recorded. Approximately $20 \%$ of all sessions were randomly selected stratified by treatment session $(\mathrm{N}=760,19.3 \%)$ with twofold probability for sessions 5 and 6 in which the treatment rational was implemented and the decision for conducting exposures was made. In the present study sessions between baseline to post (session 1 to $12, n=689$ ) were used. Due to the random selection of treatment sessions, for each patient a different number of videos were analyzed. Replacement of therapist for single sessions was necessary when therapists were sick or absent for other important reasons in order to ensure continuity of the treatment. Videotapes of these sessions were excluded from analyses $(n=17)$. All selected sessions were rated by 15 trained students of clinical psychology for the degree of adherence. The training process was supervised by three experts in the CBT manual, and was realized in a two-day workshop of self-rating treatment sessions and discussing discrepancies between trainee and experts' ratings. After the training assessors were required to independently rate three certification videos, each of which had to be rated within one point of the average experts ratings on each item.

\subsection{Assessment}

Therapist adherence was operationally defined as the degree to what the therapist adhered to the manual meaning that explanations and exercises were instructed as prescribed in the treatment protocol, and measured using the Therapist Adherence and Competency Rating Scales (TACRS; Gloster, Einsle, Lang, Hauke, \& Wittchen, 2008). The TACRS comprises checklists including all active ingredients to be implemented in a session such as psycho-education, functional analysis, goal setting, interoceptive exposure, thought experiment, exposure in situ, motivational procedures and relapse prevention. All ingredients were reviewed via a 9-point 
Therapist adherence to a treatment manual influences outcome and dropout rates

Likert-type scale from 0 (nonexistent adherence) to 8 (high adherence). Based on the scores of the ingredients raters assessed the total degree of adherence ranging also from 0 (nonexistent adherence) to 8 (high adherence). Therapist adherence ratings in the present study were distributed as follows: $2.8 \%$ of sessions were scored with 0 to 2 points, $16.3 \%$ with 3 to 4 points, $58.5 \%$ with 5 to 6 points, and $22.3 \%$ with 7 to 8 points.

Table 1

Socio-demographic and clinical characteristics of patients and therapists

\begin{tabular}{|c|c|c|c|c|c|c|c|}
\hline \multirow[b]{2}{*}{ Variable } & \multicolumn{2}{|c|}{ Total sample } & \multicolumn{2}{|c|}{ Completers } & \multicolumn{2}{|c|}{ Dropouts } & \multirow[b]{2}{*}{$p^{*}$} \\
\hline & $N$ & $\%$ & $N$ & $\%$ & $N$ & $\%$ & \\
\hline \multicolumn{8}{|l|}{ Patients characteristics } \\
\hline Age, years & \multicolumn{2}{|c|}{$35.1(10.5)$} & \multicolumn{2}{|c|}{$34.9(10.6)$} & \multicolumn{2}{|c|}{36.18} & .461 \\
\hline Female & 193 & 72.8 & 160 & 72.7 & \multicolumn{2}{|c|}{33} & .934 \\
\hline \multicolumn{8}{|l|}{ Living status } \\
\hline With parents & 15 & 5.7 & 13 & 5.9 & 2 & 4.4 & \multirow{4}{*}{.763} \\
\hline With partner & 182 & 68.7 & 153 & 69.6 & 29 & 64.4 & \\
\hline Alone & 51 & 19.3 & 41 & 18.6 & 10 & 22.2 & \\
\hline Others & 17 & 6.4 & 13 & 5.9 & 4 & 8.9 & \\
\hline \multicolumn{8}{|l|}{ Years of education } \\
\hline 8 & 29 & 10.9 & 21 & 9.6 & 8 & 17.8 & \multirow{4}{*}{.117} \\
\hline 10 & 120 & 45.3 & 98 & 44.6 & 22 & 48.9 & \\
\hline $12-13+$ & 109 & 41.1 & 96 & 43.6 & 13 & 28.9 & \\
\hline no formal degree & 7 & 2.6 & 5 & 2.3 & 2 & 4.4 & \\
\hline \multicolumn{8}{|l|}{ Employ status } \\
\hline University Student & 9 & 3.4 & 2 & 3.2 & 2 & 4.4 & \multirow{5}{*}{.217} \\
\hline Job training & 72 & 27.2 & 58 & 26.4 & 14 & 31.1 & \\
\hline Employed & 153 & 57.8 & 125 & 56.8 & 28 & 62.2 & \\
\hline Unemployed & 29 & 10.9 & 28 & 12.7 & 1 & 2.2 & \\
\hline Other & 2 & .8 & 2 & .9 & 0 & 0 & \\
\hline \multicolumn{8}{|l|}{ Social class } \\
\hline Lowest & 14 & 5.4 & 12 & 5.5 & 2 & 4.8 & \multirow{4}{*}{.471} \\
\hline Lower middle & 59 & 22.8 & 48 & 22.1 & 11 & 26.2 & \\
\hline Middle & 155 & 59.9 & 128 & 58.9 & 27 & 64.3 & \\
\hline Upper middle/ upper & 31 & 11.8 & 29 & 13.4 & 2 & 4.8 & \\
\hline Attended number of sessions & 6.87 & $(2.43)$ & \multicolumn{2}{|c|}{$12(0)$} & \multicolumn{2}{|c|}{6.87} & .001 \\
\hline Adherence $^{\mathrm{a}}$ & \multicolumn{2}{|c|}{$5.54(1.26)$} & \multicolumn{2}{|c|}{$5.57(1.24)$} & \multicolumn{2}{|c|}{5.39} & .154 \\
\hline Competence $^{\mathrm{a}}$ & \multicolumn{2}{|c|}{$5.73(1.24)$} & \multicolumn{2}{|c|}{$5.72(1.26)$} & \multicolumn{2}{|c|}{5.8} & .484 \\
\hline Experience, years & \multicolumn{2}{|c|}{$2.93(1.89)$} & \multicolumn{2}{|c|}{$3.92(1.72)$} & \multicolumn{2}{|c|}{$3(3.22)$} & .922 \\
\hline
\end{tabular}

Therapist competence was operationally defined as the degree to what the therapist delivered the treatment in a competent way such as encouraging motivation, handling of questions, or dealing with difficult situations during the treatment. Based on a checklist including all active treatment elements raters assessed the total score of competence in the end of session on a 9-point Likert-type scale from 0 (inexistent competence) to 8 (high competence) using TACRS. In the present study therapist competence ratings were distributed as follows: $1.6 \%$ of sessions were scored with 0 to 2 points, $14.1 \%$ with 3 to 4 points, $55.6 \%$ with 5 to 6 points, and $28.7 \%$ with 7 to 8 points. The TACRS were developed for this study and showed good to acceptable interrater reliability calculated by intraclass correlation (ICC) resulting in ICC $=.72$ for adherence and ICC $=.62$ for competence. 
Prior correlation analyses revealed a significant relation between adherence and competence $(\mathrm{r}=.64, \mathrm{p}<.001)$ indicating that higher levels of adherence were related to higher levels of competence.

Therapist experience was operationally defined as the number of years of practicing since starting their post-graduate psychotherapy training (typically 3-5 years in Germany) and was measured using a questionnaire of professional therapist experience (Kuhbach, 2009). The experience of our therapists ranged from 0 to 9 years with an overall mean score of three years and was denoted as follows: $\mathrm{n}=12(21.8 \%)$ with 0 to 1 year, $\mathrm{n}=33$ $(60 \%)$ with 2 to 4 years, $n=9(16.4 \%)$ with 5 to 6 years and $n=1(1.8 \%)$ with 9 years. Correlations between experience and both adherence $(\mathrm{r}=.08, \mathrm{p}=.055)$ and competence $(\mathrm{r}=.02, \mathrm{p}=.6)$ were no significant.

Primary outcome variables were assessed at baseline and post assessment and included the total scores of a) the SIGH-A (Shear et al., 2001), a 14-item questionnaire measuring the severity of anxiety symptoms rated by an assessor, b) the CGI (Guy, 1976) measuring symptom severity and therapeutic improvement ranging from 1 (normal) to 7 (most severely ill) rated by an assessor, c) the Mobility Inventory (MI; Chambless, 1985), a self-reported questionnaire consisting of 27 specific situations without being accompanied by a trusted person which range from 1 (never avoid) to 5 (always avoid). The number of panic attacks was taken from the Panicand Agoraphobia Scale (PAS; Bandelow, 1999) and rated on a five-point scale ranging from 0 (no attacks) to 4 (over seven attacks). All outcome measures have good test-retest reliability, high internal consistencies, and reasonable concurrent validity (e.g., Bandelow et al., 1998; Leon et al., 1993; Shear et al., 2001). As expected due to LOCF, completers and dropouts differed significantly in all outcome measures with a greater improvement for completers of -10.38 ( $\mathrm{SE}=7.42$ ) points in the SIGH-A, -1.11 (SE = .17) in the CGI, and -.62 $(\mathrm{SE}=.13)$ in the MI. The number of panic attacks did not differ significantly across both groups $(\mathrm{M}=-.29 ; \mathrm{SE}$ $=.4)$.

\subsection{Statistical Analysis}

In a first step, differences in therapist adherence were analyzed across sessions of a) completers vs. dropouts and b) specific subgroups of dropouts using multinomial logistic regressions. These models were commonly used when the dependent variable has more than two categories or when two or more variables need to be considered such as adherence, competence and experience in the present study. In a second step, associations between therapist adherence and treatment outcomes were analyzed across sessions of a) the total cohort, b) completers and c) dropouts using outcome mixed-effects linear regression models (MELR; Rabe-Hesketh \& Skrondal, 2005). MELR adequately deal with dependency of data resulting from nesting within higher levels, which is the case in the multicenter design of this study (Nezlek, 2001). The maximum likelihood estimator was used to estimate the random intercept and other model parameters. Difference scores were calculated between baseline and the last observation carried forward (LOCF) at post-treatment (numbers of missing data to post upon request). In a third step, the interaction term for adherence $*$ difference between completers and dropouts in adherence was entered into MELR in order to examine whether these two groups differed in the association between adherence and outcome. Coefficients rendered from MELR can be interpreted in such a way that negative differences indicated symptomatic improvement. Differences between treatment conditions ( $\mathrm{T}+$ and $\mathrm{T}-)$ and effects of therapist competence and experience on adherence were only reported in case of relevance. Data in the present study were analyzed using STATA for Windows, Version 11 (Stata Cooperation, 2009). Analyses were adjusted for the baseline score of the respective outcome. Normality of the distribution of outcome variables was checked by Skewness-Kurtosis-Tests and kernel density plots. All tests were two-sided and $\mathrm{p}<.05$ was the criterion for statistical significance.

\section{Results}

\subsection{Adherence across completers and dropouts}

Contrary to our hypothesis, completers and dropouts did not differ in therapist adherence (Table 1). Analyses 
across timing of dropout resulted in no differences in adherence between early vs. middle $(O R=1.13 ; C I=.724$, $1.77 ; p=.584)$, early vs. late $(O R=.95 ; C I=.65,1.4 ; p=.809)$ and middle vs. late $(O R=.84 ; C I=.67,1.17 ; p$ $=.302$ ) dropouts. Analyses across reasons of dropout suggest that therapists of patients with exposure related reasons for dropout showed lower levels of adherence $(O R=.76 ; C I=.57 ; 1.01 ; p=.056)$. This result was clearly significant after considering therapist competence $(O R=.55 ; C I=.39, .8 ; p=.002)$ or experience $(O R$ $=.74 ; C I=.55, .98 ; p=.036)$. As point of reference, adherence levels were also lower than those shown in completers $(O R=.75 ; C I=.59, .96 ; p=.021)$.

Table 2

Associations between Therapist Adherence and Treatment Outcome ( $n=265)$

\begin{tabular}{|c|c|c|c|c|c|c|c|c|c|}
\hline \multirow{2}{*}{ Outcome } & \multicolumn{3}{|c|}{ Adherence } & \multicolumn{3}{|c|}{ Adjusted for competence } & \multicolumn{3}{|c|}{ Adjusted for experience } \\
\hline & $\beta^{\mathrm{a}}$ & $p$-value & $95 \% \mathrm{CI}$ & $\beta^{\mathrm{a}}$ & $p$-value & $95 \% \mathrm{CI}$ & $\beta^{\mathrm{a}}$ & $p$-value & $95 \% \mathrm{CI}$ \\
\hline$\Delta \mathrm{SIGH}-\mathrm{A}^{\mathrm{b}}$ & .31 & .142 & $-.1-.73$ & -.04 & .892 & $-.58, .5$ & .23 & .283 & $-.19-.65$ \\
\hline$\Delta \mathrm{CGI}^{\mathrm{c}}$ & .03 & .283 & $-.03-.09$ & -.02 & .654 & $-.09, .06$ & .02 & .423 & $-.04-.09$ \\
\hline$\Delta \mathrm{MI}^{\mathrm{d}}$ & .04 & .078 & $0-.08$ & -.02 & .58 & $-.07, .04$ & 0 & .662 & $-.02-.07$ \\
\hline$\Delta \mathrm{PA}^{\mathrm{e}}$ & 0 & .915 & $-.1-.09$ & -.12 & .05 & $-.24, .0$ & 0 & .998 & $-1.0-1.0$ \\
\hline
\end{tabular}

Note. Negative scores represent more improvement; scores controlled for baseline; AV = Treatment Outcome; UV = Adherence; anstandardized regression coefficients; ${ }^{\mathrm{b}} \mathrm{Hamilton}$ Anxiety Scale; ${ }^{\mathrm{c}} \mathrm{Clinical}$ Global Impression; ${ }^{\mathrm{d}}$ Mobility Inventory; ${ }^{\mathrm{e}} \mathrm{Number}$ of panic attacks scored by Panic- and Agoraphobia Scale.

\subsection{Association between adherence and outcome}

Linear regression analysis revealed no significant associations between adherence and treatment outcome (Table 2 \& 3), which was unexpected. Therapists of completers and those of dropouts did not differ in adherence-outcome relationships (interaction level of adherence x group, Table 3). Analyses across treatment conditions, however, showed a significant association between adherence and outcome in completers: Higher levels of adherence were associated with poor outcome in T- (SIGH-A: $\beta=.75 ; \mathrm{CI}=.07,1.43 ; p=.031 ; \mathrm{CGI}: \beta$ $=.13 ; \mathrm{CI}=.05, .22 ; p=.002)$ but not in $\mathrm{T}+(\mathrm{SIGH}-\mathrm{A}: \beta=.17, .27 ; \mathrm{CI}=-.37, .7 ; p=.543 ; \mathrm{CGI}: \beta=0 ; \mathrm{CI}=$ $-.09, .09 ; p=.976)$. In turn, higher levels of adherence in dropouts were associated with poorer outcome in $\mathrm{T}+$ (MI: $\beta=.11 ; \mathrm{CI}=.01, .22 ; p=.036)$ but not in $\mathrm{T}-(\mathrm{MI}: \beta=-09 ; \mathrm{CI}=.-.25, .07 ; p=.258)$. Results were no longer significant after analyses were adjusted for therapist competence. Therapist experience did not influence these associations (details available upon request).

\section{Table 3}

Associations between Therapist Adherence and Treatment Outcome in Completers and Dropouts

\begin{tabular}{|c|c|c|c|c|c|c|c|c|c|}
\hline \multirow{2}{*}{ Outcome } & \multicolumn{3}{|c|}{ Completers $(n=220)$} & \multicolumn{3}{|c|}{ Dropouts $(n=45)$} & \multicolumn{3}{|c|}{ Group $^{a} \times$ Adherence $(n=265)$} \\
\hline & $\beta^{\mathrm{b}}$ & $p$-value & $95 \% \mathrm{CI}$ & $\beta^{\mathrm{b}}$ & $p$-value & $95 \% \mathrm{CI}$ & $\beta^{\mathrm{b}}$ & $p$-value & $95 \% \mathrm{CI}$ \\
\hline$\Delta \mathrm{SIGH}-\mathrm{A}^{\mathrm{c}}$ & .38 & .075 & $-.04-.81$ & .53 & .209 & $-.3-1.35$ & -.17 & .728 & $-1.12-.78$ \\
\hline$\Delta \mathrm{CGI}^{\mathrm{d}}$ & .06 & .06 & $0-.13$ & -.02 & .664 & $-.13-.1$ & -.08 & .263 & $-.21-.06$ \\
\hline$\Delta \mathrm{MI}^{\mathrm{e}}$ & .04 & .086 & $0-.08$ & .07 & .158 & $-.03-.16$ & .01 & .835 & $-.08-.11$ \\
\hline$\Delta \mathrm{PA}^{\mathrm{f}}$ & 0 & .899 & $-.1-.1$ & -.02 & .879 & $-.21-.25$ & -.04 & .761 & $-.27-.2$ \\
\hline
\end{tabular}

Note. Negative scores represent more improvement; scores controlled for baseline; AV = Treatment Outcome; UV = Adherence; ${ }^{\mathrm{a}}$ completer vs. dropout; ' unstandardized regression coefficients; ${ }^{\mathrm{c}}$ Hamilton Anxiety Scale; ${ }^{\mathrm{d}}$ Clinical Global Impression; ${ }^{\mathrm{e}}$ Mobility Inventory; ${ }^{\mathrm{f}} \mathrm{Number}$ of panic attacks scored by Panic- and Agoraphobia Scale. 


\section{Discussion}

\subsection{Summary of results}

The present study examined the impact of therapist adherence to a treatment manual on outcome, completion of treatment, and dropout risk. Results indicated that in a thoroughly standardized randomized controlled trial therapist adherence was generally high with little variation. The variation that occurred was not related to symptomatic change, even if therapist competence or experience were taken into account. Significant associations between lower levels of adherence and symptomatic improvement were only found in particular constellations such as completers in T- and dropouts in T+. Moreover, analyses across subgroups of dropouts revealed significantly lower levels of therapist adherence in patients who dropped out due to exposure-related reasons if therapist competence or experience were considered. However, all these effects were small in terms of effects size.

\subsection{Adherence across completers and dropouts}

The comparable high levels of adherence in both therapists who treated completers and those who treated dropouts suggest that the treatment was implemented as intended in the overall sample. Neither the timing nor the reasons of dropout were associated with therapist adherence, at least at the high level of adherence as found in the present study. In order to strengthen the assumption that levels of adherence are independent of dropout characteristics it would be necessary to repeat this study by analysing each therapy session including videotapes of exposure session outside the therapy room.

Our data suggest, however, that the relationship between adherence and reasons of dropout was influenced by therapist competence and experience. Our results showed that in patients who dropped out due to exposure-related reasons CBT was implemented with lower adherence to the manual than in patients who dropped out due to other reasons and in those who completed treatment. Interestingly, therapists of patients who dropped out of treatment due to issues surrounding the exposure itself showed lower levels of competence and higher levels of experience. The explanation for this involves practical implications. Problems in adherently implementing the treatment manual might be based on the presence of both patient and therapist characteristics (Perepletchikova \& Kazdin, 2005). If a patient is overly anxious or insufficiently motivated to commence exposure, a therapist may deliberately choose to spend more time as intended for specific treatment elements. In this case, implementing a treatment more flexibly might not show high adherence, but maybe evidence of experience. However, it is important to note that the advantage of more experienced therapists in therapy of patients is still disputable (Beutler et. al, 2004; Stein \& Lambert, 1984, 1995). To ensure that a therapist do not stick to an established way of conducting therapy because of several years of experience, it is very recommended to critically review the therapeutic procedure and to check the patient's level of clinical functioning and therapy motivation. In therapeutic practice a constantly debriefing of recorded therapy sessions in supervision might be helpful.

\subsection{Association between adherence and outcome in completers and dropouts}

In the overall sample, adherence to an exposure-based CBT manual was neither related to treatment outcome in patients who completed treatment nor in those who dropped out. These non-significant associations between adherence and outcome are consistent to several prior studies (e.g. Carroll, Nich \& Rounsaville, 1997; Feeley, DeRubeis, \& Gelfand, 1999; Huppert el al., 2001; Loeb et al., 2005; Webb, DeRubeis, \& Barber, 2010) and imply that in and of itself, strict adherence to a treatment approach does not predict symptomatic change (Shaw et al., 1999).

Adherence - outcome relationships differed, however, across treatment conditions and revealed several disadvantages for high levels of therapist adherence. If replicated, increasing general anxiety symptoms are 
associated with highly adherent instructing, preparing and rehearsing exposure in completers doing the exposure in situ by themselves (T-). In dropouts who were accompanied during the exposure by the therapists $(\mathrm{T}+)$ more agoraphobic avoidance was associated with a strict treatment approach too. Because $\mathrm{T}+$ was more structured than $\mathrm{T}$-, results suggest that a too strict adherence in a thoroughly standardized treatment might be detrimental for dropouts but not for completers. However, based on small effects and no significant interactions between group and adherence, these conclusions remain speculative.

Surprisingly, neither competence nor experience influenced the relationship between treatment outcome and adherence. One explanation for these findings might be that therapists in the present study were carefully trained to an acceptable standard of competent behaviour independently of their experience. Moreover, results might be biased by a restricted range of experience. About $60 \%$ of therapists reported no more than three years of experience. In this regard, it might be possible that (a) therapists' prior practical experience was sufficient for delivering treatment as intended to achieve symptomatic improvement, (b) the effect of adherence on symptomatic change was independent of therapist experience, or (c) the number of years of experience was not an adequate operational definition of experience but rather experience with specific cases. And finally, many unmeasured variables may influence the association between adherence and outcome in ways that are not necessarily controllable for the therapist, such as the time of symptom change (Webb, DeRubeis, \& Barber, 2010). For instance, symptomatic improvement during the treatment could be an indicator for some therapists to strictly implement the manual as intended (Loeb et al., 2005) whereas other therapists initiate a more flexible treatment approach (Gresham, MacMillan, Beebe-Frankenberger, \& Bocian, 2000; Webb, DeRubeis, \& Barber, 2010).

Because a more flexible treatment approach was found to be somewhat more advantageous in the present study, an important practical implication for the therapeutic practice might be to use a treatment manual rather as a guideline than as an inflexible script (Kendall \& Beidas, 2007; Kendall, Gosch, Furr, \& Sood, 2008). Therapists, especially those who implement exposure-related CBT, should be able to adapt proved strategies to the present situation without deviating from salient therapeutic principles and agreed-upon therapy goals. Another useful suggestion might be to clarify the reasons and consequences of non-adherent behaviour for a better understanding of the processes that lead to change by using process measures. Questionnaires should be completed by patient and therapist measuring issues such as the perceived change over the course of therapy, the attributation of those changes to, the helpfulness of aspects of treatment, the therapeutic relationship as well as current understanding problems and patient motivation. The outcome of this procedure might not only inform about situational and individual patient characteristics moderating the relationship between adherence and outcome (Huppert, Barlow, Gorman, Shear \& Woods, 2006) but also about the required level of therapist adherence in the next therapy session. Analysing this information under supervision might help to provide an adequate matching of patient's requirements and the level of therapist adherence.

\subsection{Limitations}

The results of this study should be interpreted in the context of six main limitations. Because exposures in situ sessions were implemented outside the therapy room, results are limited to those aspects that were videotaped (i.e., prior to leaving and after returning to the therapy room in the $\mathrm{T}+$ condition vs. the entire preparation and rehearsal in the T- condition). Second, these data were characterized by low variability in adherence ratings. Nearly $80 \%$ of sessions were rated between "moderately" and "highly" adherent. As a result, our ability to detect otherwise meaningful patterns may have been restricted by the reduced variance in adherence. This study is further limited by the use of observer ratings of adherence. Different results may be possible if the therapist rated adherence. Moreover, the relatively small number of patients in some of the subgroup analyses of dropouts may have limited statistical power. Because the study was neither designed nor powered to answer these complex and multifaceted questions our results must interpreted with caution. Additionally, LOCF analyses can only reflect therapeutic processes up to the point of dropout and not beyond. Finally, our results are limited to patients with PD/AG who participate in outpatient mental health services at 
psychology and psychiatry departments of research universities.

\section{Conclusion}

The results of the present study add to the small but growing literature suggesting that therapist adherence does not directly predict treatment outcome in general. However, considering treatment characteristics we observed some evidence for a link between lower level of therapist adherence and symptomatic improvement. Moreover, our results of adherence scores across patients who dropped out due to exposure related reasons proposed that further studies should concentrate on therapist and patient characteristics associated with therapist adherence. The challenge for future research will be to identify the relative impact of adherence and other therapist variables on treatment outcome for understanding the mechanisms of change in CBT for patients with PD/AG.

\section{References:}

American Psychiatric Association (2000). Diagnostic and statistical manual of mental disorders, Text revision (6th ed.). Washington, DC: American Psychiatric Association. http://dx.doi.org/10.1176/appi.books.9780890423349

Baker-Morrissette, S., Spiegel, D.A., \& Heinrichs, N. (2005). Sensation focused intensive treatment for panic disorder with moderate to severe agoraphobia. Cognitive Behavior Practice, 12, 17-29. http://dx.doi.org/10.1016/S1077-7229(05)80036-7

Bandelow, B. (1999). Panic and Agoraphobia Scale (PAS). Ashland, OH: Hogrefe \& Huber Publishers.

Bandelow, B., Brunner, E., Broocks, A., Beinroth, D., Hajak, G., Pralle, L., \& Rüther, E. (1998). The use of the Panic and Agoraphobia Scale in a clinical trial. Psychiatry Research, 77, 43-49. http://dx.doi.org/10.1016/S0165-1781(97)00118-2

Barlow, D. H., Gorman, J. M., Shear, M. K., \& Woods, S.W. (2000). Cognitive behavioral therapy, imipramine, or their combination for panic disorder - a randomized controlled trial. Journal of the American Medical Association, 283, 2529-2536. http://dx.doi.org/10.1001/jama.283.19.2529

Barber, J. P., Gallop, R., Crits-Christoph, P., Frank, A., Thase, M. E., Weiss, R. D., \& Connolly Gibbons, M. B. (2006). The role of therapist adherence, therapist competence, and the alliance in predicting outcome of individual drug counseling: Results from the National Institute on Drug Abuse Collaborative Cocaine Treatment Study. Psychotherapy Research, 16, 229-240. http://dx.doi.org/10.1080/10503300500288951

Beutler, L. E., Malik, M., Alimohamed, S., Harwood, T. M., Talebi, H., Noble, S., \& Wong, E. (2004). Therapist effects. In M.J. Lambert (Ed.), Bergin and Garfield's handbook of psychotherapy and behavior change (5th ed., pp. 227-306). New York: Wiley.

Borrelli, B., Sepinwall, D., Ernst, D., Bellg, A. J., Czajkowski, S., Breger, R., DeFrancesco, C., Levesque, C., Sharp, D. L., Ogedegbe, G., Resnick, B., \& Orwig, D. (2005). A new tool to assess treatment fidelity and evaluation of treatment fidelity across ten years of health behavior research. Journal of Consulting and Clinical Psychology, 73, 852-860. http://dx.doi.org/10.1037/0022-006X.73.5.852

Carroll, K. M., Nich, C., \& Rounsaville, B. J. (1997). Contribution of the therapeutic alliance to outcome in active versus control psychotherapies. Journal of Consulting and Clinical Psychology, 65, 510-514. http://dx.doi.org/10.1037/0022-006X.65.3.510

Chambless, D. L. (1985). The Mobility Inventory for Agoraphobia. Behavior Research and Therapy, 23, 35-44. http://dx.doi.org/10.1016/0005-7967(85)90140-8

Craske, M. G., \& Barlow, D. H. (2007). Mastery of your anxiety and panic. Oxford: University Press.

DeRubeis, R. J., \& Feeley, M. (1990). Determinants of change in cognitive therapy for depression. Cognitive Therapy and Research, 14, 469-482. http://dx.doi.org/10.1007/BF01172968

Emmelkamp, P. M. G., Bouman, T. K., \& Blaauw, E. (1994). Individualized versus standardized therapy: A comparative evaluation with obsessive-compulsive patients. Clinical Psychology and Psychotherapy 1, 95-100. http://dx.doi.org/10.1002/cpp.5640010206 
Therapist adherence to a treatment manual influences outcome and dropout rates

Feeley, M., DeRubeis, R. J., \& Gelfand, L. (1999). The temporal relation of adherence and alliance to symptom change in cognitive therapy for depression. Journal of Consulting and Clinical Psychology, 67, 578582. http://dx.doi.org/10.1037/0022-006X.67.4.578

Gloster, A. T., Einsle, F. Lang, T., Hauke, C., \& Wittchen, H. U. (2008). TACRS: The therapist adherence and competency rating scales for panic disorder with agoraphobia. Unpublished instrument, Institute of Clinical Psychology and Psychotherapy, Technische Universität Dresden, Germany.

Gloster, A. T., Wittchen, H. U., Einsle, F., Höfler, M., Lang, T., Helbig-Lang, S. ... Arolt, V. (2009). Mechanism of action (MAC): Methods of a multi-center randomized controlled trial in 369 patients with panic disorder and agoraphobia. European Archives of Psychiatry and Clinical Neuroscience, 259, 155-166. http://dx.doi.org/10.1007/s00406-009-0065-6

Gloster, A. T., Wittchen, H. U., Höfler, M., Einsle, F., Lang, T., Helbig-Lang, S., ... Arolt, V. (2011). Psychological treatment for panic disorder with agoraphobia: A randomized controlled trial to examine the role of therapist-guided exposure in-situ in CBT. Journal of Consulting and Clinical Psychology, 79, 406-420. http://dx.doi.org/10.1037/a0023584

Gresham, F. M., MacMillan, D. L., Beebe-Frankenberger, M. E., \& Bocian, K. M. (2000). Treatment integrity in learning disabilities intervention research: Do we really know how treatments are implemented? Learning Disabilities Research \& Practice, 15, 198-205. http://dx.doi.org/10.1207/SLDRP1504_4

Guy, W. (1976). Clinical global impression. In W. Guy (Ed.), ECDEU Assessment manual for psychopharmacology, revised (pp. 217-222). Rockville, MI: National Institute of Mental Health.

Heimberg, R. G., \& Becker, R. E. (1984). Comparative outcome research. In M. Hersen, L. Michelson \& A.S. Bellack (Eds.), Issues in psychotherapy research (pp. 251-283). New York: Plenum.

Henry, W. P., Strupp, H. H., Butler, S. F., Schacht, T. E., \& Binder, J. L. (1993). Effects of training in time-limited dynamic psychotherapy: Changes in therapist behavior. Journal of Consulting and Clinical Psychology, 61, 434-440. http://dx.doi.org/10.1037/0022-006X.61.3.434

Hogue, A., Henderson, C. E., Dauber, S., Barajas, P. C., Fried, A., \& Liddle, H. A. (2008). Treatment adherence, competence, and outcome in individual and family therapy for adolescent behavior problems. Journal of Consulting and Clinical Psychology, 76, 544-555. http://dx.doi.org/10.1037/0022-006X.76.4.544

Huey, S. J., Henggeler, S. W., Brondino, M. J., \& Pickrel, S. G. (2000). Mechanisms of change in multisystemic therapy: Reducing delinquent behavior through therapist adherence and improved family and peer functioning. Journal of Consulting and Clinical Psychology, 68, 451-467. http://dx.doi.org/10.1037/0022-006X.68.3.451

Huppert, J. D., Barlow, D. H., Gorman, J. M., Shear, M. K., \& Woods, S. W. (2006). The interaction of motivation and therapist adherence predicts outcome in cognitive behavioral therapy for panic disorder: Preliminary findings. Cognitive and Behavioral Practice, 13, 198-204. http://dx.doi.org/10.1016/j.cbpra.2005.10.001

Huppert, J.D., Bufka, L.F., Barlow, D.H., Gorman, J.M., Shear, M.K., \& Woods, S.W. (2001). Therapists, therapist variables, and cognitive-behavioral therapy outcome in a multicenter trial for panic disorder. Journal of Consulting and Clinical Psychology, 69, 747-755. http://dx.doi.org/10.1037/0022-006X.69.5.747

Kendall, P. C., \& Beidas, R. S. (2007). Smoothing the trail for dissemination of evidence-based practices for youth: Flexibility within fidelity. Professional Psychology: Research and Practice, 38, 13-20. http://dx.doi.org/10.1037/0735-7028.38.1.13

Kendall, P. C., Gosch, E., Furr, J. M., \& Sood, E. (2008). Flexibility within fidelity. Journal of the American Academy of Child \& Adolescent Psychiatry, 47, 987-93. http://dx.doi.org/10.1097/CHI.0b013e31817eed2f

Kuhbach, K. G. (2009). Der Einfluss von beruflicher Erfahrung auf die Treatment Integrität einer Multizentrischen Studie zur manualisierten Behandlung bei Panikstörung mit Agoraphobie. Unpubulished results [In German]. Technische Universität Dresden.

Lambert, M. J., \& Bergin, A. E. (1994). The effectiveness of psychotherapy. In S. L. Garfield \& A. E. Bergin (Eds.), Handbook of psychotherapy and behavior change (4th ed., pp. 143-189). New York: Wiley. 
Hauke et al.

Lang, T., Helbig-Lang, S., Westphal, D., Gloster, A. \& Wittchen, H. U. (2011). Kognitiv-behaviorale Behandlung der Panikstörung mit Agoraphobie [In German]. Göttingen: Hogrefe.

Leon, A. C., Shear, M. K., Klerman, G. L., Portera, L., Rosenbaum, J. F., \& Goldenberg, I. (1993). A comparison of symptom determinants of patient and clinical global ratings in patients with panic disorder and depression. Journal of Clinical Psychopharmacology, 13, 327-331. http://dx.doi.org/10.1097/00004714-199310000-00005

Loeb, K. L., Wilson, G. T., Labouvie, E., Pratt, E. M., Hayaki, J., Walsh, B. T., ... Fairburn, C.G. (2005). Therapeutic alliance and treatment adherence in two interventions for bulimia nervosa: A study of process and outcome. Journal of Consulting and Clinical Psychology, 73, 1097-1107. http://dx.doi.org/10.1037/0022-006X.73.6.1097

Luborsky, L., \& DeRubeis, R. J. (1984). The use of psychotherapy treatment manuals: A small revolution in psychotherapy research style. Clinical Psychology Review, 4, 5-14. http://dx.doi.org/10.1016/0272-7358(84)90034-5

Margison, F., Barkham, M., Evans, C., McGrath, G., Mellor-Clark, J., Audin, K., \& Connell, J. (2000). Measurement and psychotherapy: evidence based practice and practice based evidence. British Journal of Psychiatry, 177,123-130. http://dx.doi.org/10.1192/bjp.177.2.123

Nezlek, J. B. (2001). Using hierarchical linear modeling to analyze grouped data. Group dynamics: Theory, Research, and Practice, 2, 313-320. http://dx.doi.org/10.1037/1089-2699.2.4.313

Perepletchikova, F., \& Kazdin, A. E. (2005). Treatment integrity and therapeutic change: Issues and research recommendations. Clinical Psychology: Science and Practice, 12, 365-383. http://dx.doi.org/10.1093/clipsy.bpi045

Rabe-Hesketh, S., \& Skrondal, A. (2005). Multilevel and longitudinal modeling using Stata. College Station, Texas: Stata Press.

Reis, B. F., \& Brown L. G. (1999). Reducing psychotherapy dropouts: Maximizing perspective convergence in the psychotherapy dyad. Psychotherapy, 36, 123-136. http://dx.doi.org/10.1037/h0087822

Richard ,D. C. S., Lauterbach, D., \& Gloster, A. T. (2007). Description, mechanisms of action, and assessment. In D. C. S. Richard \& D. L. Lauterbach (Eds.), Handbook of exposure therapies (pp. 1-28), Burlington: Elsevier. http://dx.doi.org/10.1016/B978-012587421-2/50002-8

Schulte, D., Künzel, R., Pepping, G., \& Schulte-Bahrenberg, T. (1992). Tailor-made versus standardized therapy of phobic patients. Advances in Behavior, Research, and Therapy, 14, 67-92. http://dx.doi.org/10.1016/0146-6402(92)90001-5

Shaw, B. F., Yamaguchi, 1. E., Yamaguchi J., Olmsted, M., Vallis, T. M., Dobson, K. S., ... Imber, S. D. (1999). Therapist competence ratings in relation to clinical outcome in cognitive therapy of depression. Journal of Consulting and Clinical Psychology, 67, 837-846. http://dx.doi.org/10.1037/0022-006X.67.6.837

Shear, M. K., Vander Bilt, J., Rucci, P., Endicott, J., Lydiard, B., Otto, M. W., ... Frank, D. M. (2001). Reliability and validity of a Structured Interview Guide for the Hamilton Anxiety Rating Scale (SIGH-A). Depression and Anxiety, 13, 166-178. http://dx.doi.org/10.1002/da.1033

Siqueland, L., Crits-Christoph, P., Barber, J. P., Butler, S. F., Thase, M., Najavits, L., \& Onken, L. S. (2000). The role of therapist characteristics in training effects in cognitive, supportive expressive and drug counseling therapies for cocaine dependence. Journal of Psychotherapy: Research and Practice, 9, 123-130.

Smith, S. W., Daunic, A. P., \& Taylor, G. G. (2007). Treatment fidelity in applied educational research: Expanding the adoption and application of measures to ensure evidence-based practice. Education and Treatment of Children, 30, 121-134. http://dx.doi.org/10.1353/etc.2007.0033

StataCorp. (2009). Stata Statistical Software: Release 11. College Station, TX: StataCorp LP.

Stein, D. M., \& Lambert, M. J. (1995). Graduate training in psychotherapy: Are therapy outcome enhanced? Journal of Consulting and Clinical Psychology, 63, 182-196. http://dx.doi.org/10.1037/0022-006X.63.2.182

Stein, D. M., \& Lambert, M. J. (1984). On the relationship between therapist experience and psychotherapy outcome. Clinical Psychology Review, 4, 127-142. http://dx.doi.org/10.1016/0272-7358(84)90025-4 
Webb, C., DeRubeis, R., \& Barber, J. (2010). Therapist adherence/competence and treatment outcome: A meta-analytic review. Journal of Consulting and Clinical Psychology, 78, 200-211. http://dx.doi.org/10.1037/a0018912

White, K. S., Allen, L. B., Barlow, D.H., Gorman, J. M., Shear, M. K., \& Woods, S. W. (2010). Attrition in a multicenter clinical trial for panic disorder. The Journal of Nervous and Mental Disease, 198, 665-671. http://dx.doi.org/10.1097/NMD.0b013e3181ef3627

Wierzbicki, M., \& Pekarik, G. (1993). A meta-analysis of psychotherapy dropout. Professional Psychology: Research and Practice, 24, 190-195. http://dx.doi.org/10.1037/0735-7028.24.2.190

Wittchen, H. U., \& Pfister, H. (1997). DIA-X Interview. Instruktionsmanual zur Durchführung von DIA-X-Interviews [Instruction manual for the DIA-X-Interview]. 


\section{Acknowledgements}

Funding/Support: This work is part of the German multi-center trial: Mechanisms of Action in CBT (MAC). The MAC is funded by the German Federal Ministry of Education and Research (BMBF; project no. 01GV0615) as part of the larger BMBF Psychotherapy Research Funding Initiative.

Centers: Principal investigators (PI) with respective areas of concentration of the MAC are Volker Arolt (Münster: Overall MAC Program Coordination), Hans-Ulrich Wittchen (Dresden: PI for the Randomized Clinical Trial and Manual Development), Alfons Hamm (Greifswald: PI for Psychophysiology), Alexander L. Gerlach (Münster: PI for Psychophysiology and Panic subtypes), Andreas Ströhle (Berlin: PI for Experimental Pharmacology), Tilo Kircher (Marburg: PI for functional neuroimaging), and Jürgen Deckert (Würzburg: PI for Genetics). Additional site directors in the RTC component of the program are Georg W. Alpers (Würzburg), Thomas Fydrich and Lydia Fehm (Berlin-Adlershof), and Thomas Lang (Bremen).

Data Access and Responsibility: All principle investigators take responsibility for the integrity of the respective study data and their components. All authors and co-authors had full access to all study data. Data analysis and manuscript preparation were completed by the authors and co-authors of this article, who take responsibility for its accuracy and content.

Acknowledgements and staff members by site: Greifswald (coordinating site for psychophysiology): Christiane Melzig, Jan Richter, Susan Richter, Matthias von Rad; Berlin-Charite (coordinating center for experimental pharmacology): Harald Bruhn, Anja Siegmund, Meline Stoy, Andre Wittmann; Berlin-Adlershof: Irene Schulz; Münster (Overall MAC Program Coordination, Genetics and Functional Neuroimaging):Andreas Behnken, Katharina Domschke, Adrianna Ewert, Carsten Konrad, Bettina Pfleiderer, Peter Zwanzger Münster (coordinating site for psychophysiology and subtyping): Judith Eidecker, Swantje Koller, Fred Rist, Anna Vossbeck-Elsebusch; Marburg/ Aachen (coordinating center for functional neuroimaging):, Barbara Drüke, Sonja Eskens, Thomas Forkmann, Siegfried Gauggel, Susan Gruber, Andreas Jansen, Thilo Kellermann, Isabelle Reinhardt, Nina Vercamer- Fabri; Dresden (coordinating site for data collection, analysis, and the RCT): Franziska Einsle, Christine Fröhlich, Andrew T. Gloster, Christina Hauke, Simone Heinze, Michael Höfler, Ulrike Lueken, Peter Neudeck, Stephanie Preiß, Dorte Westphal; Würzburg Psychiatry Department (coordinating center for genetics): Andreas Reif; Würzburg Psychology Department: Julia Dürner, Hedwig Eisenbarth, Antje B. M. Gerdes, Harald Krebs, Paul Pauli, Silvia Schad, Nina Steinhäuser; Bremen: Veronika Bamann, Sylvia Helbig-Lang, Anne Kordt, Pia Ley, Franz Petermann, Eva-Maria Schröder. Additional support was provided by the coordinating center for clinical studies in Dresden (KKS Dresden): Xina Grählert and Marko Käppler.

The RTC project was approved by the Ethics Committee of the Medical Faculty of the Technical University of Dresden (EK 164082006). The study was registered with the ISRCTN: ISRCTN80046034.

\section{Conflict of interest statement}

The following authors report no conflicts of interest concerning the content of this paper: C. Hauke, A. Gloster, J. Richter, A. Gerlach, L. Fehm, M. Stoy, T. Lang, J. Klotsche, F. Einsle, J. Deckert, H.-U. Wittchen. T. Kircher received fees for educational programs from Janssen-Cilag, Eli Lilly, Servier, Lundbeck, Bristol Myers Squibb, Pfizer, and Astra- Zeneca; travel support/sponsorship for congresses from Servier; speaker's honoraria from Janssen-Cilag; and research grants from Pfizer and Lundbeck. 